\title{
Synthetic evaluation of integrated energy system based on AHP- fuzzy comprehensive assessment method
}

\author{
Xiao $\mathrm{Lu}^{1}$, Jiajia $\mathrm{Wu}^{2}$, Wei $\mathrm{Hu}^{1}$, Changyun $\mathrm{Chi}^{3 *}$, Xuedong $\mathrm{Jiang}^{3}$, Xiaobo $\mathrm{Li}^{3}$ \\ ${ }^{1}$ State Grid Jiangsu Electric Power Co., Ltd., Nanjing, Jiangsu, 210019, China \\ ${ }^{2}$ Yangzhou Power Supply Branch, State Grid Jiangsu Electric Power Company Yangzhou, Jiangsu, 225007, China \\ ${ }^{3}$ College of Electrical Engineering, Zhejiang University, Hangzhou, Zhejiang, 310027, China
}

\begin{abstract}
Integrated energy system (IES) is an essential ingredient of energy reform. The construction of IES can promote the coupling utilization of multiple energy sources, and improve the reliability and flexibility of energy system. Based on amounts of literature study and experts' recommendations, 9 firstclass indexes, 13 second-class indexes and 11 third-class indexes are confirmed to assess the integrated energy system from three dimensions of technology, economy, and environmental protection. Analytic Hierarchy Process (AHP) and fuzzy comprehensive assessment method are adopted to assess the overall quality of chosen integrated energy system. An industrial park is chosen to be an example and examine the evaluation condition of IES.
\end{abstract}

\section{Introduction}

Integrated energy system (IES) is an important part of energy internet, and it's not only the research hotspot in the field of energy, but also the development direction of energy restricting. The core of IES is carrying out energy conversion, utilization, and multi-energy complement [12]. U.S. Department of Energy had proposed a smart grid evaluation index system, which aimed to evaluate smart grid from six aspects [3]. The evaluation system can measure the reliability, security, and the interactive service for the user side of smart grid [4]. Europe also published smart grid earning evaluation index system to achieve the aim of improving grid earnings from nine fields and $21 \mathrm{key}$ indexes [5].

In current literatures, methods of evaluation index always focus on power grid, and ignore the hot grid and cool gird [6-8]. Li et al. [9] built universal flow system models from the aspects of energy distribution, conversation, and storage. On this basis, the assessment system of IES from four dimensions of energy, devices, information, and system was come up. Luo et al. [10] studied the equivalent features of microgrid, and put forward the characteristics of intermittent power source, the islanding state of microgrid, and the benefits of microgrid. Zhang et al. [11] established an index evaluation model of park-level integrated energy system for microgrid from the aspects of economy, reliability, energy consumption and environmental protection.

Currently, the main methods of comprehensive evaluation method conclude principal component analysis (PCA) [12], AHP [13, 14], entropy weight method (EWM) [7, 15, 16], Data Envelope Approach (DEA) [17] and the method for order performance by similarity to ideal solution (TOPSIS) [15]. However, PCA and EWM always have errors when the evaluation indexes with small range of changes, and DEA is easily affected by extremes. Cavallaro et al. [15] used fuzzy Shannon entropy and fuzzy TOPSIS to assess five CHP technologies in terms of economy and efficiency. Ren et al. [13] chose various of evaluation indexes such as primary energy consumptions, investment costs, carbon emissions, and applied AHP to analyse the Japanese power supply system.

The AHP-Delphi method can combine the data and practical experience to a certain degree, and obtain more objective and reasonable evaluation indexes of IES. This method is used to determine the indexes and weight, and a park will be tested by fuzzy comprehensive assessment method.

\section{Establishment of synthetic evaluation}

Selection of evaluation index is both the foundation and key point of evaluation system of IES. Because the pros and cons of index always determine the quality of evaluation. Based on the construction concept of IES, this paper will expand the synthetic evaluation from three dimensions: technology, economy, and environment protection. Generally, IES is a multi-flow system, and it contains power flow, heating flow, cooling flow and so on. Third-class index aims at these questions to launch the discussion, and the synthetic assessment system of IES is illustrated in Figure 1. 


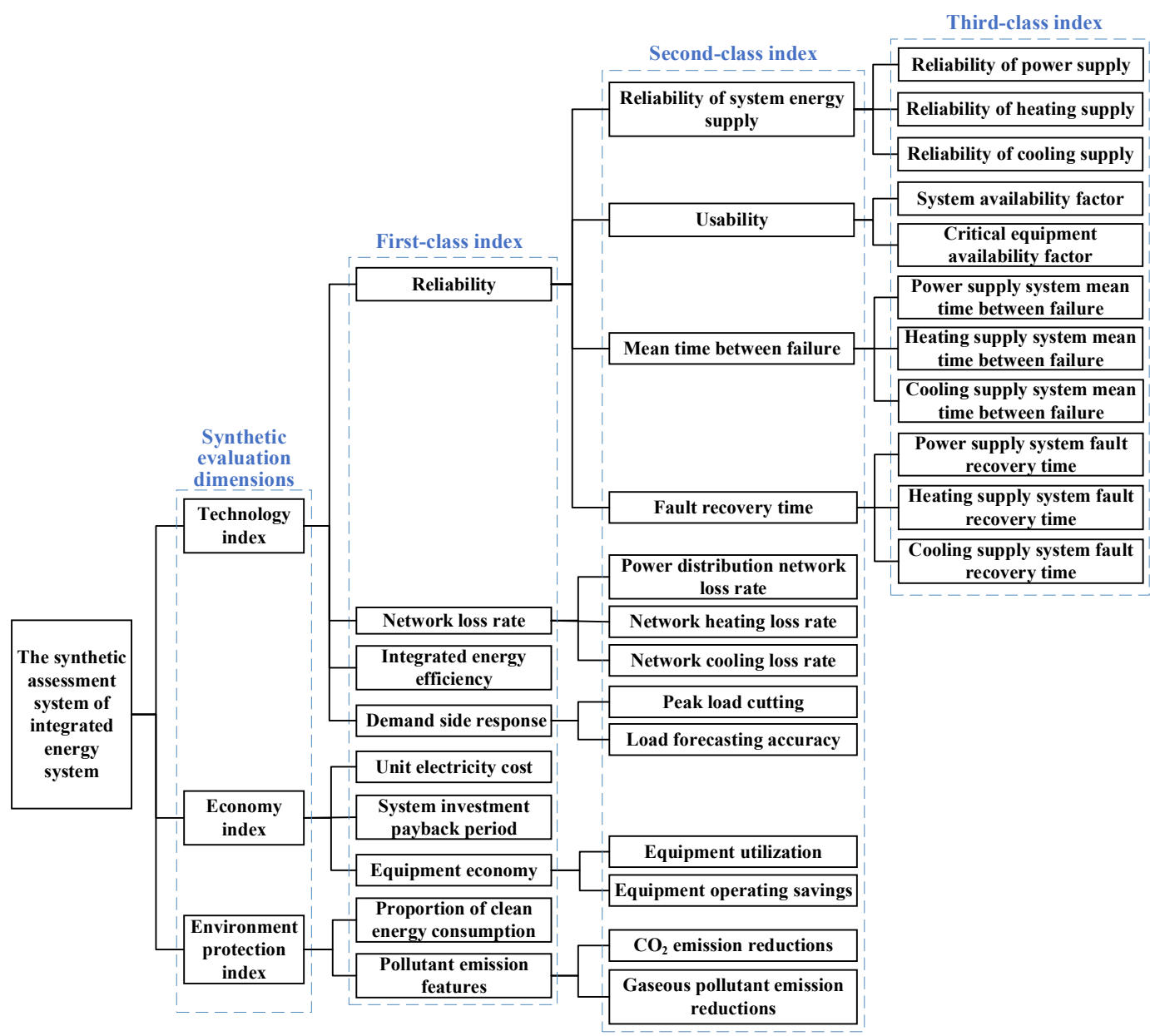

Figure 1. The synthetic assessment system of integrated energy system.

\section{Establishment of weightiness and fuzzy discriminant vector}

For IES, synthetic evaluation always used to indicate the advantages and disadvantages of the single index. AHP combines both qualitative analysis and quantitative analysis. Fuzzy comprehensive assessment method uses exact mathematics model to deal with indefinable and fuzzy things. Therefore, AHP - fuzzy comprehensive assessment method is used in this study. The flow diagram of synthetic evaluation is shown in Figure 2.

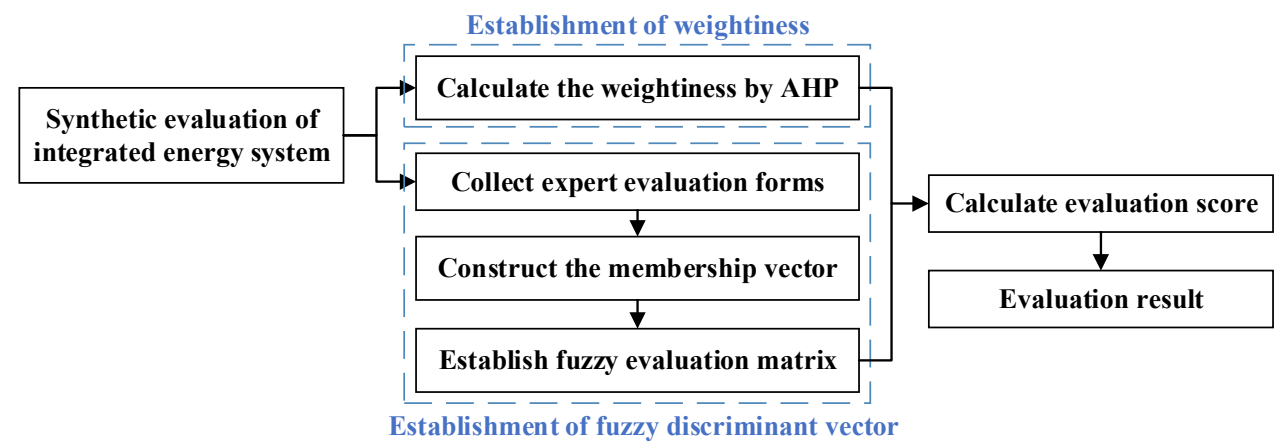

Figure 2. The flow diagram of synthetic evaluation

\subsection{Establishment of weightiness}

3.1.1 First-class index
Depending on Delphi method, importance degrees of each index are established, and the judgement matrix $C$ of first-class index are illustrated in equation (1). 


$$
C=\left[\begin{array}{ccccccccc}
1 & 6 & 2 & 7 & 4 & 9 & 8 & 5 & 3 \\
1 / 6 & 1 & 1 / 5 & 2 & 1 / 3 & 4 & 3 & 1 / 2 & 1 / 4 \\
1 / 2 & 5 & 1 & 6 & 3 & 8 & 7 & 4 & 2 \\
1 / 7 & 1 / 2 & 1 / 6 & 1 & 1 / 4 & 3 & 2 & 1 / 3 & 1 / 5 \\
1 / 4 & 3 & 1 / 3 & 4 & 1 & 6 & 5 & 2 & 1 / 2 \\
1 / 9 & 1 / 4 & 1 / 8 & 1 / 3 & 1 / 6 & 1 & 1 / 2 & 1 / 5 & 1 / 7 \\
1 / 8 & 1 / 3 & 1 / 7 & 1 / 2 & 1 / 5 & 2 & 1 & 1 / 4 & 1 / 6 \\
1 / 5 & 2 & 1 / 4 & 3 & 1 / 2 & 5 & 4 & 1 & 1 / 3 \\
1 / 3 & 4 & 1 / 2 & 5 & 2 & 7 & 6 & 3 & 1
\end{array}\right]
$$

Initial index weight of first-class index $W$, eigenvalue of maximum $\lambda_{\max }$ and coincidence indicator $C I$ can be calculated by AHP.

$$
W=\left[\begin{array}{lllllllll}
0.2977 & 0.0492 & 0.2159 & 0.0340 & 0.1047 & 0.0173 & 0.0239 & 0.0718 & 0.1517
\end{array}\right]^{T}
$$

After normalization,

$$
W=\left[\begin{array}{lllllllll}
0.3081 & 0.0509 & 0.2235 & 0.0352 & 0.1084 & 0.0179 & 0.0247 & 0.0743 & 0.1570
\end{array}\right]^{T}
$$

Thus, $\lambda_{\max }=9.4014, R I=1.45, C I=0.05$, $C R=0.034<0.1$, which meets consistency requirements.

\begin{tabular}{|c|c|c|c|c|}
\hline First-class index & $W$ & Second-class index & $\boldsymbol{W}$ & $W_{z}$ \\
\hline \multirow{4}{*}{ Reliability } & \multirow{4}{*}{0.3081} & Reliability of system energy supply & 0.5076 & 0.1564 \\
\hline & & Usability & 0.3243 & 0.0999 \\
\hline & & MTBF & 0.0655 & 0.0202 \\
\hline & & Fault recovery time & 0.1026 & 0.0316 \\
\hline \multirow{3}{*}{ Network loss rate } & \multirow{3}{*}{0.0509} & Power distribution network loss rate & 0.7143 & 0.0363 \\
\hline & & Network heating loss rate & 0.1429 & 0.0073 \\
\hline & & Network cooling loss rate & 0.1429 & 0.0073 \\
\hline Integrated energy efficiency & 0.2235 & 1 & 1 & 0.2235 \\
\hline \multirow{2}{*}{ Demand side response } & \multirow{2}{*}{0.0352} & Peak load cutting & 0.8333 & 0.0293 \\
\hline & & Load forecasting accuracy & 0.1667 & 0.0059 \\
\hline Unit electricity cost & 0.1084 & / & / & 0.1084 \\
\hline System investment payback period & 0.0179 & / & / & 0.0179 \\
\hline \multirow{2}{*}{ Equipment economy } & \multirow{2}{*}{0.0247} & Equipment utilization & 0.1429 & 0.0035 \\
\hline & & Equipment operating savings & 0.8571 & 0.0212 \\
\hline \multirow{2}{*}{ Pollutant emission features } & \multirow{2}{*}{0.0743} & $\mathrm{CO}_{2}$ emission reductions & 0.6667 & 0.0495 \\
\hline & & Gaseous pollutant emission reductions & 0.3333 & 0.0248 \\
\hline Proportion of clean energy consumption & 0.1570 & / & / & 0.1570 \\
\hline
\end{tabular}

\subsubsection{Second-class index}

Table 1. Formatting sections, subsections and subsubsections.

\subsection{Establishment of fuzzy discriminant vector}

Combined with the synthetic assessment system shown in Figure 1, index set $F$ of first-class indexes is exhibited in equation (4).

In a similar way, judgement matrix, normalization matrix and initial index weight of second-class indexes can be calculated and the final weightiness of evaluation indexes are shown in Table 1.

\subsubsection{Partition of factors set}

$F=\left\{F_{1}, F_{2}, F_{3}, F_{4}, F_{5}, F_{6}, F_{7}, F_{8}, F_{9}\right\}$

$=\left\{\begin{array}{l}\text { reliability; network loss rate; integrated energy efficiency; demand side response; } \\ \text { unit electricity cost; system investment payback period; equipment economy; } \\ \text { pollutant emission features; proportion of clean energy consumption }\end{array}\right\}$

\subsubsection{Calculated membership}

Evaluation sets is shown in equation (5) and the score range is illustrated in Table 2.

$$
V=\{v 1, v 2, v 3, v 4, v 5\}=\{\text { very good; good; just so - so; not bad; bad }\}
$$


Table 2. Score range and evaluation level

\begin{tabular}{cccccc}
\hline $\begin{array}{c}\text { Score } \\
\text { range }\end{array}$ & $90-100$ & $80-90$ & $70-80$ & $60-70$ & $\begin{array}{c}\text { Below } \\
60\end{array}$ \\
\hline $\begin{array}{c}\text { Evaluation } \\
\text { level }\end{array}$ & $\begin{array}{c}\text { very } \\
\text { good }\end{array}$ & good & $\begin{array}{c}\text { just } \\
\text { so-so }\end{array}$ & $\begin{array}{c}\text { not } \\
\text { bad }\end{array}$ & bad \\
\hline
\end{tabular}

An industrial park is chosen to be a calculation example. Based on expert evaluation, 5 pieces of data were collected to evaluate this example. After normalization, the memberships of each indicator are as shown in Table 3.

\section{Calculation example}

Table 3. The result of index membership

\begin{tabular}{|c|c|c|}
\hline First-class index & Second-class index & $\begin{array}{c}\text { Membership }\left(B_{i}, i=1,\right. \\
2, \ldots, 9) \\
\end{array}$ \\
\hline \multirow{4}{*}{ Reliability } & Reliability of system energy supply & $(0.4,0.4,0.2,0,0)$ \\
\hline & Usability & $(0.2,0.4,0.2,0.2,0)$ \\
\hline & MTBF & $(0.2,0.2,0.4,0.2,0)$ \\
\hline & Fault recovery time & $(0.2,0.2,0.4,0,0.2)$ \\
\hline \multirow{3}{*}{ Network loss rate } & Power distribution network loss rate & $(0.2,0.2,0.6,0,0)$ \\
\hline & Network heating loss rate & $(0.2,0.4,0.4,0,0)$ \\
\hline & Network cooling loss rate & $(0.6,0.2,0.2,0,0)$ \\
\hline Integrated energy efficiency & I & $(0.6,0.2,0.2,0,0)$ \\
\hline \multirow{2}{*}{ Demand side response } & Peak load cutting & $(0.6,0.4,0,0,0)$ \\
\hline & Load forecasting accuracy & $(0.2,0.2,0.4,0.2,0)$ \\
\hline Unit electricity cost & / & $(0.4,0.2,0.4,0,0)$ \\
\hline System investment payback period & / & $(0.2,0.2,0.6,0,0)$ \\
\hline \multirow{2}{*}{ Equipment economy } & Equipment utilization & $(0.6,0.2,0.2,0,0)$ \\
\hline & Equipment operating savings & $(0.2,0.2,0.4,0.2,0)$ \\
\hline \multirow{2}{*}{ Pollutant emission features } & $\mathrm{CO}_{2}$ emission reductions & $(0.6,0.2,0.2,0,0)$ \\
\hline & Gaseous pollutant emission reductions & $(0.4,0.2,0.4,0,0)$ \\
\hline Proportion of clean energy consumption & 1 & $(0.2,0.2,0.4,0.2,0)$ \\
\hline
\end{tabular}

Take reliability as an example.

$$
\widetilde{R_{1}}=\left[\begin{array}{ccccc}
0.4 & 0.4 & 0.2 & 0 & 0 \\
0.2 & 0.4 & 0.2 & 0.2 & 0 \\
0.2 & 0.2 & 0.4 & 0.2 & 0 \\
0.2 & 0.2 & 0.4 & 0 & 0.2
\end{array}\right]
$$
$\mathrm{T}$,

According to $W_{2 l}=\left[\begin{array}{llll}0.5076 & 0.3243 & 0.0655 & 0.1026\end{array}\right]$

$$
\widetilde{B_{1}}=\widetilde{R_{1}} \circ W_{21}{ }^{T}=\left[\begin{array}{lllll}
0.4 & 0.4 & 0.2 & 0.2 & 0.1026
\end{array}\right]
$$

where, ${ }^{\circ}$ is fuzzy matrix composition operator, the calculation method is as follows:

$$
\widetilde{R}=\left(\widetilde{B_{1}}, \widetilde{B_{2}}, \widetilde{B_{3}}, \widetilde{B_{4}}, \widetilde{B_{5}}, \widetilde{B_{6}}, \widetilde{B_{7}}, \widetilde{B_{8}}, \widetilde{B_{9}}\right)^{T}=\left[\begin{array}{ccccc}
0.3071 & 0.3071 & 0.1535 & 0.1535 & 0.0788 \\
0.2 & 0.2 & 0.6 & 0 & 0 \\
0.6 & 0.2 & 0.2 & 0 & 0 \\
0.45 & 0.3 & 0.125 & 0.125 & 0 \\
0.4 & 0.2 & 0.4 & 0 & 0 \\
0.2 & 0.2 & 0.6 & 0 & 0 \\
0.2 & 0.2 & 0.4 & 0.2 & 0 \\
0.5294 & 0.1765 & 0.2941 & 0 & 0 \\
0.2 & 0.2 & 0.4 & 0.2 & 0
\end{array}\right]
$$

Thus, according to the combined weightiness in Table 1:

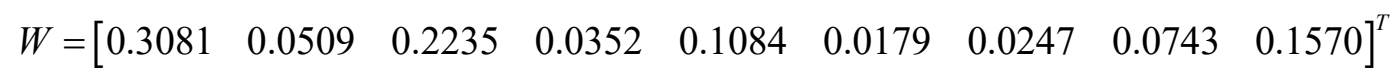


Total fuzzy comprehensive evaluation vector:

$\widetilde{B}=\widetilde{R} \circ W^{T}=\left[\begin{array}{lllll}0.3071 & 0.3071 & 0.2 & 0.1570 & 0.0788\end{array}\right]$

After normalization,

$$
B=\left[\begin{array}{lllll}
0.2925 & 0.2925 & 0.1905 & 0.1495 & 0.0750
\end{array}\right]
$$

Corresponding to

$$
V=\left[\begin{array}{lllll}
100 & 90 & 80 & 70 & 60
\end{array}\right]
$$

Then,

$$
S=V \cdot B^{T}=85.78
$$

It means that the score of this industrial park is 85.78 , and the evaluation level of this integrated energy system is "good".

\section{Conclusion}

The synthetic evaluation of IES is a very important work to monitor the operation status, and provide guidance for the future improvement and optimization. In this paper, a complete evaluation index system is established by AHP and Delphi method from three dimensions of technology, economy, and environmental protection. Also, an industrial park is selected to be a calculation example. After calculation based on the fuzzy comprehensive assessment method, evaluation score is obtained and corresponding evaluation level is good. The effectiveness and broad applicability of the synthetic assessment system are verified by the example.

\section{Acknowledgments}

This work was sponsored by State Grid Jiangsu Electric Power Co., Ltd. with the project of "Application of Integrated Energy Regulation Technology Aiming at the Interaction of Source, Grid, Load and Storage (521002190049)".

\section{References}

1. Huang A. Q., Crow M. L., Heydt G. T., et al. (2011) The future renewable electric energy delivery and management (FREEDM) system: The Energy Internet. Proc. IEEE, 99(1): 133-148.

2. Ahmadi P., Dincer I., Rosen M.A. (2014) Thermoeconomic multi-objective optimization of a novel biomass-based integrated energy system. Energy, 68: 958-970.

3. U.S. Department of Energy. (2004) National electric delivery technologies roadmap. U.S. Department of Energy, New York.

4. Dixon R. K., Mcgowan E., Onysko G., et al. (2010) US energy conservation and efficiency policies: Chanllenges and opportunities, Energy Policy, 38(11): 6389-6408.
5. European Smart Grids Technology Platform. (2008) Strategic development document for Europe's electricity networks of the future. Ruropean Commission, Brussels.

6. Du L., Sun L., Chen H., et al. (2017) Multi-index evaluation of integrated energy system with P2G planning. Automation of Electric Power Systems, 37(06): 110-116.

7. Chen B. S., Liao Q. F., Liu D. C., et al. (2018) Comprehensive evaluation indices and methods for regional integrated energy system. Automation of Electric Power Systems, 42(04): 174-182.

8. Zhang X. J., Ge S. Y., Liu H., et al. (2014) Comprehensive assessment system and method of smart distribution grid. Power System Technology, 38(1): 40-46.

9. Li Y., Wu M., Zhou H. M., et al. (2015) Study on some key problems related to regional multi energy system based on universal flow model. Power System Technology, 39(8): 2230-2237.

10. Luo Y., Wang G., Wang L. J. (2013) Reliability Evaluation Indices for Microgrid. Automation of Electric Power Systems, 5: 9-14.

11. Zhang S.X., Lv S.K. (2018) Evaluation Method of Park-Level Integrated Energy System for Microgrid. Power System Technology, 42(8): 2431-2438.

12. Shen C., Ling L., Wang W. W., et al. (2013) Comprehensive evaluation model of CCHP system based on PCA-AHP. CAS \& Heat, 9: 25-29.

13. Ren H., Gao W., Zhou W., et al. (2009) Multicriteria evaluation for the optimal adoption of distributed residential energy systems in Japan. Energy Policy, 37(12): 5484-5493.

14. Liu J. F. (2019) Comprehensive evaluation of integrated energy system based on measured data. Beijing.

15. Cavallaro F., Zavadskas E.K., Raslanas S. (2016) Evaluation of Combined Heat and Power (CHP) systems using fuzzy Shannon entropy and fuzzy TOPSIS. Sustainability, 8: 556-577.

16. Dong F. G., Zhang Y., Shang M. M. (2016) Multicriteria comprehensive evaluation of distributed energy system. Proc. CSEE, 12: 3214-3222.

17. Hu D. G., Zhang X. J., Chen N. S., et al. (2015) Research on multi-dimensional post evaluation methodology of new energy power generation projects. Power System Protection and Control, 43(4): 10-17. 